\title{
Dentist availability in Egypt: a 20-year study of supply, potential demand and economic factors
}

Maha El Tantawi, ${ }^{1}$ Nourhan M. Aly, ${ }^{1}$ Dina Attia, ${ }^{1}$ Hams Abdelrahman ${ }^{1}$ and Mohamed Mehaina ${ }^{2}$

${ }^{1}$ Department of Pediatric Dentistry and Dental Public Health, Faculty of Dentistry, Alexandria University, Egypt (Correspondence to: M. El Tantawi: maha_tantawy@hotmail.com). ${ }^{2}$ Alexandria and Mediterranean Research Center, Bibliotheca Alexandrina, Egypt.

\begin{abstract}
Background: Egypt is one of the most populated countries in the Eastern Mediterranean Region with historically large numbers of trained professionals providing services in and outside the country. Data about dentist availability are needed to plan for workforce production and training.
\end{abstract}

Aims: We assessed dentist availability in Egypt including (1) changes over 20 years; (2) spatial distribution; and (3) association with supply, potential demand for care and economic conditions.

Methods: In an ecological study (1995-2014), we used data from the Central Agency for Public Mobilization and Statistics. The outcome variable was dentist availability (dentists per 1000 population). The explanatory variables were: (1) population size; (2) number of dental graduates; (3) previous dentist availability; (4) increase in wages; and (5) percentage of population migrating internally seeking jobs. We assessed variation in availability using statistical process control and spatial autocorrelation. The impact of explanatory variables was assessed using general linear models with partial $\eta^{2}$ to measure effect size.

Results: Dentists per 1000 population were randomly distributed over the country and the ratio reached 0.18 in 2014, indicating a shortage despite the increasing number of dental graduates since 1995 (667.1\%). Previous dentist availability $\left(\eta^{2}=0.60\right)$ and increase in wages $\left(\eta^{2}=0.48\right)$ had the greatest impact on dentist availability.

Conclusions: Egypt faces a problem of dentist shortage that has not been offset by the increase in dental graduates. Improving the economic conditions and incorporating health care into the national development plan may improve the situation.

Keywords: Dentists/supply and distribution, Egypt, students, dental schools, dental economics.

Citation: El Tantawi M; Aly N; Attia D; Abdelrahman H; Mehaina M. Dentist availability in Egypt: a 20-year study of supply, potential demand and economic factors. East Mediterr Health J. 2020;26(9):1078-1086. https://doi.org/10.26719/emhj.20.008

Received: 17/12/18; accepted: 07/05/19

Copyright $($ C World Health Organization (WHO) 2020. Open Access. Some rights reserved. This work is available under the CC BY-NC-SA 3.0 IGO

license (https://creativecommons.org/licenses/by-nc-sa/3.0/igo)

\section{Introduction}

Dentist availability facilitates dental care provision and has a positive impact on demand for services (1), according to the theory of supplier-induced demand (2). Dentist to population ratio is one of the most commonly used methods to assess dentist availability (3), and to classify regions into those with adequate dentist availability and areas of shortage where dentist number may not meet population needs (4).

Macrolevel analysis at community level has shown that human healthcare resources are affected by the population ecology theory including: (1) structural attributes of the healthcare system, such as personnel supply, which determines growth; (2) demand for services where demographics determine consumption; and (3) economic profile as a determinant of resource availability (5). Previous studies have confirmed the effect of demographic factors, particularly population size and income, on healthcare provider availability (6).

Most studies assessing dentist availability were crosssectional, focusing on a single point in time, and were conducted in developed countries with high numbers of dentists and high dentist to population ratios $(1,6)$. Few cross-sectional studies have assessed dentist availability in less-developed countries $(7,8)$. One longitudinal study described the change in dental workforce in Oman and predicted future trends (9), whereas another in Austria followed dentist availability over time and assessed differences between public and private dentists (10). A longitudinal study in Taiwan, China investigated the impact of global budgeting on dental workforce distribution (11).

Egypt was the 14th most populated country in the world and the 7th among lower middle income countries in 2017 (12). It ranked 11th out of 47 in dentist to 1000 population among lower middle income countries (13). Over the last 2 decades, Egypt has witnessed economic challenges that became more pronounced after the political instability that started in 2011, with a large trade deficit, high rate of unemployment and rising prices (14). During this period, private dental schools were opened for the first time and by 2014, they were training 58.6\% of all dental students (15). State-funded health insurance covered $58.2 \%$ of the population in 2015 for minimal fees with facilities all over the country (14). The complex 
interaction of these factors poses challenges for oral healthcare policy setting.

Longitudinal studies are needed to assess dentist availability in developing countries with limited economic resources, large population size and low dentist to population ratios. This is important to plan global dental workforce needs where large populations are involved. Such studies would also add to the knowledge about the impact on dentist availability of graduating more dentists, building more dental schools, and country-level economic changes.

The null hypothesis of the study was that dentist availability in Egypt is affected by supply measured by the number of dental graduates and population size but not by the economic condition of the country. This study aimed to conduct a macrolevel analysis of major administrative units in Egypt, governorates, to assess (1) the trend in dentist availability over 20 years in Egypt; (2) spatial distribution of dentist availability during these 20 years; and (3) factors affecting availability.

\section{Methods}

\section{Study design}

The present study was based on publicly available data from the Central Agency for Public Mobilization and Statistics (CAPMAS), Egypt covering from 1995 to 2014 (16). When data for these years were not available, we used those for the nearest available year. We obtained the following for each of the top-level administrative units in Egypt (governorates, $n=27$ in 2014) at aggregate level following an ecological design (Supplementary Table 1 online). Supply and potential demand indicators: (1) number of dentists for 1995-2014; (2) total number of dental graduates per dental school in each governorate; and (3) population data from 1995 to 2014. Economic indicators: (1) mean weekly wages in 1995 and 2013 corrected for inflation; and (2) percentage of individuals who internally migrated to another governorate seeking jobs.

\section{Data analysis}

We calculated the number of dentists per 1000 population and assessed its variation over time using statistical process control (SPC). SPC aims at monitoring processes to detect if there are changes beyond those expected because of normal variation. Process is a term based on the origin of SPC techniques from industrial production.
However, it applies to other variables that are measured across time points or across units at the same time point. SPC uses charts where measurements are plotted against the multiple units or time points. These charts show departures from normal variation when the measurement goes beyond 3 adjusted standard deviations or $3 \sigma$. The $\sigma$ levels are shown as dotted lines above and below the mean, which is represented by a solid line (17). Control charts were plotted to identify the years and/or governorates when/where the number of dental graduates, population size and dentists per 1000 population changed beyond normal variation (> $3 \sigma$ or below $\sigma 3 \sigma$ levels).

The number of dentists per 1000 population was averaged over 4 intervals; 1995-1999, 2000-2004, 20052009 and 2010-2014. The ratio of the number of dentists per 1000 population was categorized into 4 classes: $0.03-0.06,0.07-0.12,0.13-0.20$ and $0.21-0.41$ and plotted using ARG GIS (Esri, Redlands, CA, USA) on 4 maps; 1 for each time interval. The distribution pattern of dentist availability was assessed (as a quantitative variable) for governorates using Moran's Index (18). This index is a correlation coefficient that quantifies how much a governorate is similar to neighbouring governorates. Its values ranges from +1 , indicating perfect similarity to -1 , indicating perfect dissimilarity or dispersion. Zero indicates perfect random distribution (18).

Dentists per 100000 population in 2010-2014 was the outcome variable in general linear models. Univariate models were fitted including the explanatory variables: (1) number of graduates 1995-2014; (2) average population in 2010-2014; (3) dentist availability in 1995; (4) increase in wages between 1995 and 2013; and (5) percentage of internal migrants seeking jobs in 2006. Increase was calculated as [(recent value-earlier value)/ earlier value] ${ }^{*} 100$. As well as the univariate models (model 1 ), 2 multiple regression models were fitted; model 2 including the number of graduates, average population size in 20102014 , and dentist availability in 1995; and model 3 in which economic indicators were added to model 2. Regression coefficients (B) were calculated to show the change in dentist to population ratio in 2010-2014 associated with a unit change in the explanatory variables, $95 \%$ confidence intervals, $P$ values and partial $\eta^{2}$ as measure of effect size. Standardized regression estimates $(\beta)$ were also calculated to compare the relative strength of explanatory variables included in each model (19). Statistical analysis was performed using SPSS version 22.0.

\begin{tabular}{lccc}
\hline Table 1 Dentists, population and economic indicators in Egypt at beginning and end of study & & Percent increase \\
& Beginning of study & End of study & $\mathbf{2 0 1 4}$ \\
No. of dental graduates: total per year & $\mathbf{1 9 9 5}$ & 3828 & 667.13 \\
Dentists (total) & 499 & 15317 & 296.20 \\
Population (total) & 3866 & 86813723 & 50.95 \\
Dentists per 1000 population, mean (SD) & 57509998 & $0.18(0.08)$ & $209.65(118.25)$ \\
Weekly wages in LE (adjusted for inflation), mean (SD) & $0.07(0.05)$ & $1691.41(1142.68)$ & $164.54(202.40)$ \\
\hline
\end{tabular}




\section{Results}

Table 1 shows that in 1995 there were 499 dental graduates and 3866 dentists serving 57.5 million people, with a mean dentists per 1000 population ratio of 0.07 . After 20 years, there was a $667.13 \%$ increase in the number of graduates, $296.20 \%$ increase in the number of dentists and $50.95 \%$ increase in the population, with a $209.65 \%$ increase in dentists per 1000 population. During these 20 years, 32848 dentists graduated from 17 dental schools including 8 private schools (Supplementary Table 2 online). Weekly wages (adjusted for inflation) increased by $164.54 \%$ (Table 1). Of 4769497 persons migrating from one governorate to another, $22.2 \%$ were seeking jobs.

With reference to the changes over 20 years, the numbers of graduates and population size were significantly lower before 2001 and higher after 2009 compared to the numbers between 2001 and 2009 (Figure 1). The number of dentists per 1000 population followed a more or less similar pattern with significant increase after 2009. Figure 2 shows dentist availability from 1995 to 2014. For the 4 time periods, Moran's Index indicated random distribution; in 1995-1999, Index = -0.05 ; in 2000-2004, Index $=0.002$; in 2005-2009, Index = -0.013 ; and in 2010-2014, Index $=0.02$ (all P > 0.05). During all 4 time periods, some governorates, such as Alexandria, consistently had the highest dentist to population ratio, whereas other governorates such as Fayoum and Qina consistently had the lowest ratio. Governorates that had dentist to population ratio significantly higher than all others are marked by red circles (Figure 3): South Sinai in 1995-1999, Cairo and New Valley in 2000-2004 and Alexandria in 2005-2014. In general, dentist to population

Figure 1 Control charts of number of dental graduates, population size and dentist availability, 1995- 2014
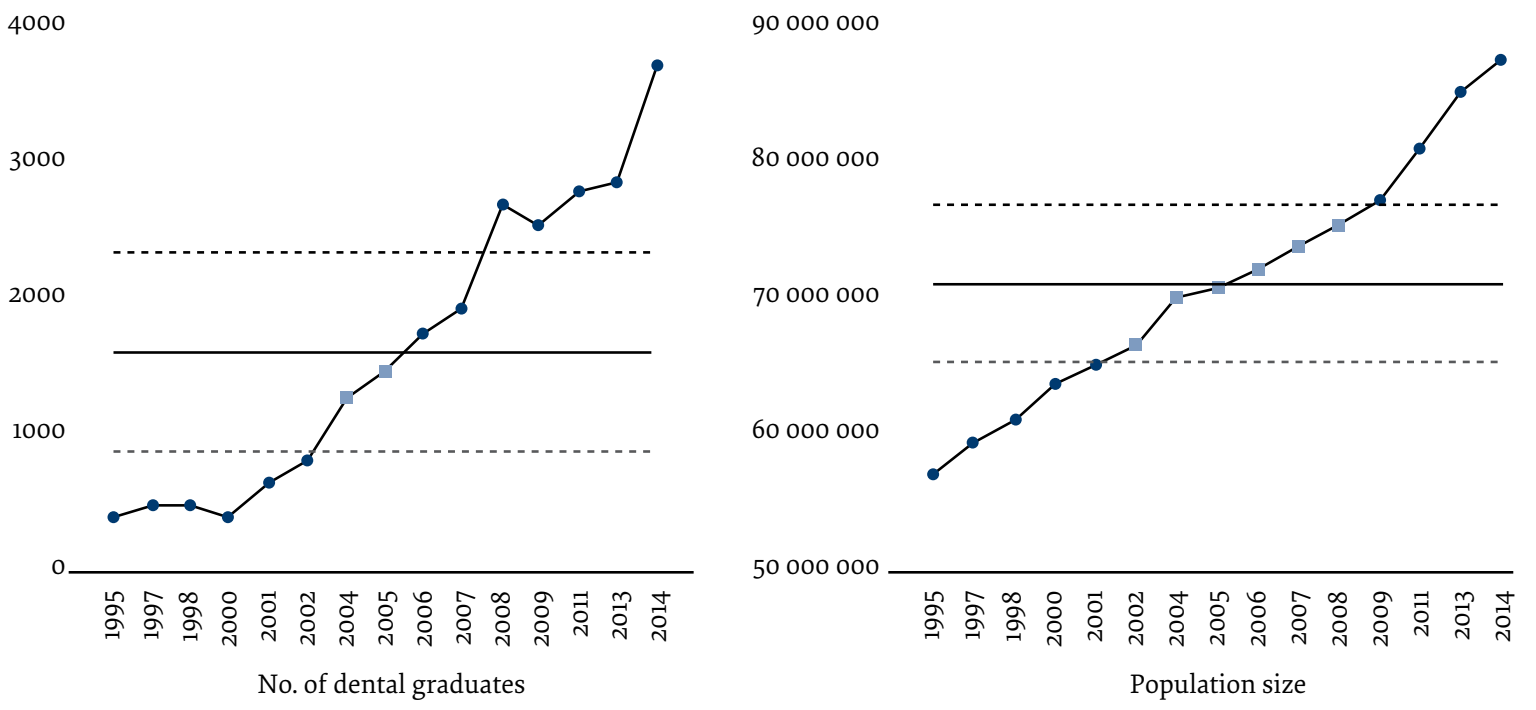

Control rule violation: $\square$ No $\bullet$ Yes

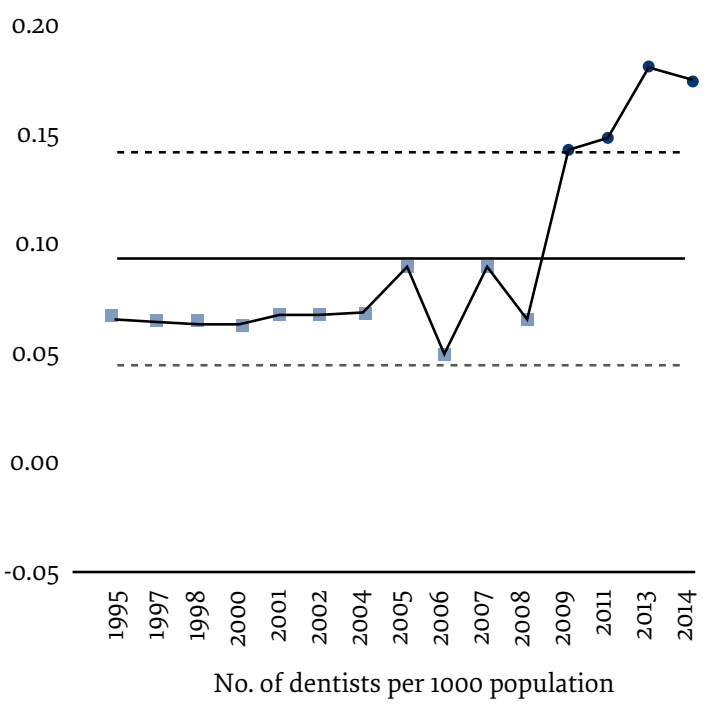




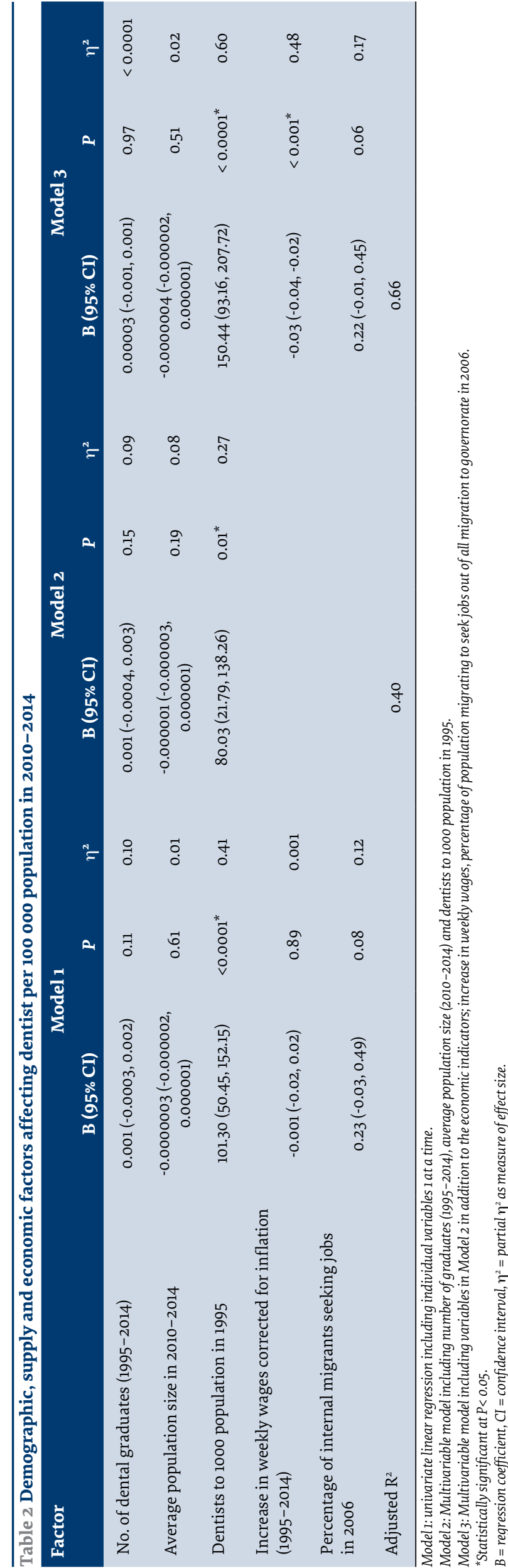

ratio increased over time until, in 2010-2014, 9 (33.3\%) governorates had a ratio $>0.2$.

In Model 1, dentist to population ratio in 1995 had the greatest association with dentist to population ratio in 2010-2014 $\left(\eta^{2}=0.41\right)$ followed by the percentage of internal migrants who were seeking jobs $\left(\eta^{2}=0.12\right)$ and the number of dental graduates $\left(\eta^{2}=0.10\right.$, Table 2). Model 2 shows less variation in dentist availability compared to Model 3 in which economic factors were added (adjusted $\mathrm{R}^{2}=0.40$ and 0.66 ). When all factors were simultaneously considered in Model 3, higher dentist to population ratio in 2010-2014 was significantly associated with higher dentist to population ratio in $1995(B=150.44)$ and lower increase in weekly wages $(B=-0.03)$. Internal migration to seek jobs $(B=0.22)$ and number of graduates $(B=0.00003)$ were associated with higher dentist to population ratio, whereas population size was associated with lower ratio $(B=-0.0000004)$, although these were not significantly associated. Comparison of standardized regression coefficients ( $\beta$ ) showed that the greatest effect on the outcome variable was for dentist to population ratio in $1995(\beta=0.97)$, followed by change in weekly wages $(\beta=-0.62)$ and population size $(\beta=-0.36)$ whereas the percentage of internal migrants seeking jobs $(\beta=0.15)$ and number of graduates $(\beta=0.15)$ had weaker effects.

\section{Discussion}

Starting from 2009, dentist availability in Egypt significantly increased reaching the highest level in 2014 but that still indicated a national shortage. This shortage was randomly distributed, although some governorates had better availability, such as Alexandria, and others had inadequate availability, such as Qina and Fayoum. Past dentist availability was the strongest predictor of future availability. Economic factors explained more variation in dentist availability than supply and potential demand, so the null hypothesis can be rejected.

The number of graduates significantly increased after 2009 when 5 new private dental schools were opened (15), although only $46.6 \%$ of dental graduates were retained in the workforce over 20 years. Because of this high attrition rate, the national dentist to 1000 population ratio reached 0.18 in 2014, signifying a shortage of dentists (20) and placing 64.6 million (74.3\%) Egyptians in areas of dentist shortage. The present study disagrees with a Chilean study that projected $77.5 \%$ dentist oversupply after increasing dental schools from 5 to 34 over 15 years (21), and with an Indian study reporting a surplus of 100000 dentists after a 10-fold increase in dental schools over 25 years (22). This difference in attrition rate may be explained by dentists' migration outside Egypt, which is supported by a previous study showing that the highest percentage of Arab expatriates working as dentists in 8 Arab countries were Egyptian (23), and a United Nations report showing brain drain in some Middle East and North Africa (MENA) countries, such as Egypt and Jordan, resulting from migration to the Gulf countries (24). The impact of mobility on dentist availability in source 
Figure 2 Spatial distribution of dentist availability in Egypt showing random distribution, 1995-2014
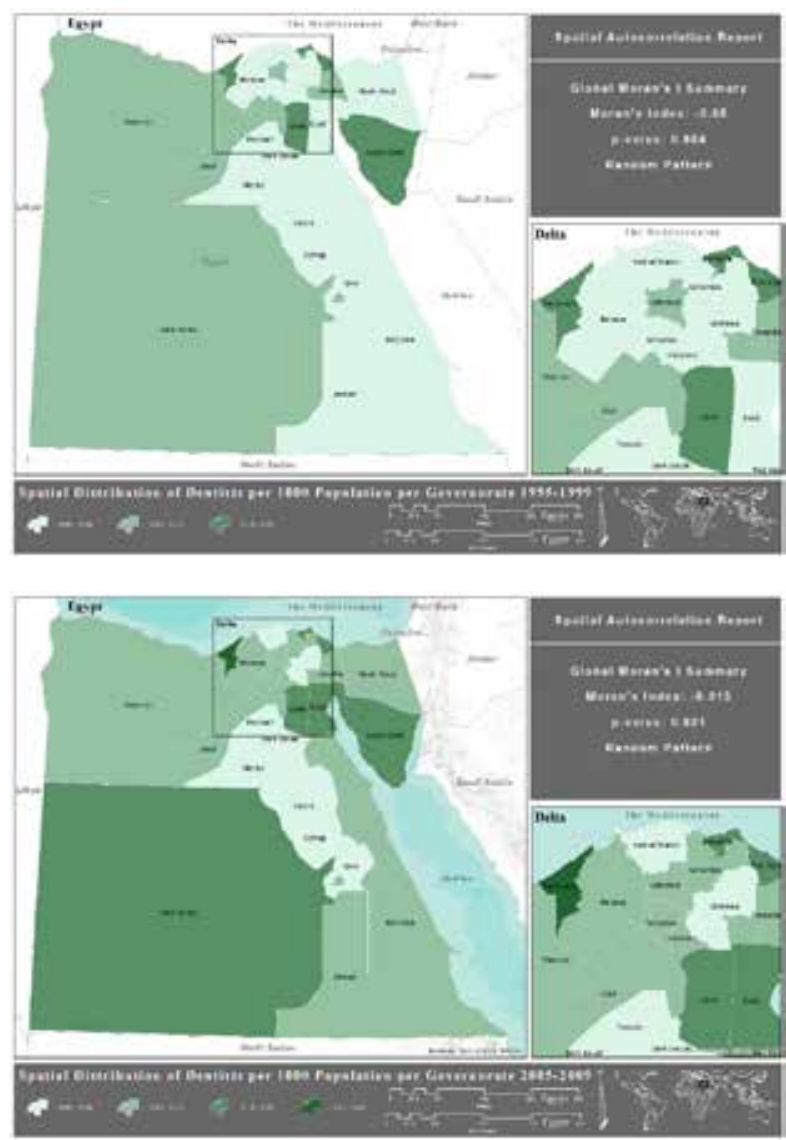

countries witnessing political and economic instability should be addressed by co-ordinated global efforts.

At governorate level, the number of dental graduates had a weak association with dentist availability. This disagrees with previous reports that the presence of a dental school had a positive effect on dentist availability at county level in the United States of America (1) and in Japanese prefectures (25). However, it agrees with a study assessing the relationship at the American state level (26); a larger unit that may be more similar to the areas in our study. The lack of association may also be explained by the clustering of $9 / 17$ (52.9\%) dental schools in the greater Cairo area.

In the current study, previous dentist availability had the strongest positive impact on future dentist availability. This agrees with research showing that scarcity of healthcare providers predicts their future scarcity, and that physicians are more likely to move into locations where physician availability is already high (27). This finding, however, disagrees with a previous report of negative correlation between the number of medical specialists and their previous number in the same location, suggesting competition among specialists (6).

The present study showed an association between dentist availability and the percentage of migrants seeking jobs. This may be attributed to the greater convenience of using dental services near workplaces
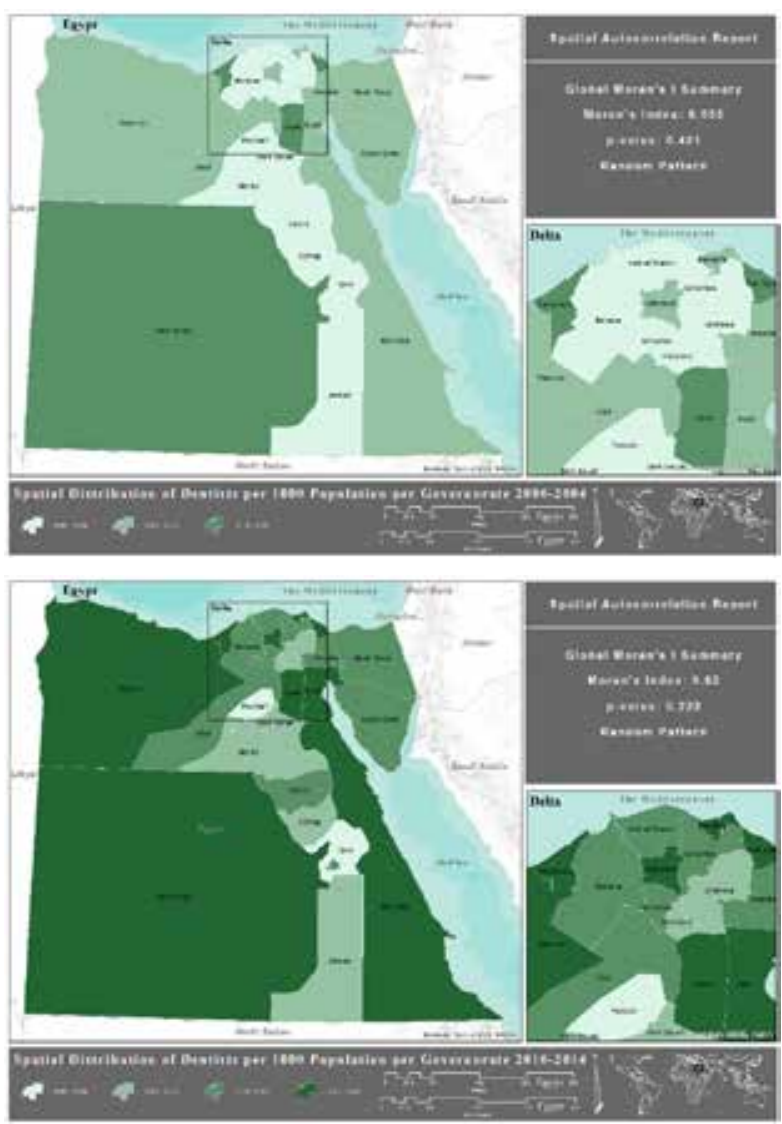

rather than at home towns, thus creating demand for dentists (1). It agrees with another study that reported an association between health worker to population ratio and emigration rates at country level (28).

In the present study, greater dentist availability was associated with lower increase in wages. Most dentists in Egypt work in the public sector (29), providing national health insurance whose coverage increased 10 times between 1995 and 2014 and included mainly employees (14). The dental care expenses of these employees were covered regardless of wages increase. Sixty percent of health expenditure in Egypt is out of pocket (14), and for this segment, increasing wages would help cover dental care costs. Thus, the negative association between increased wages and availability of mostly public sector dentists indicates a positive impact on the availability of private sector dentists. This disagrees with research reporting an association between dentist availability and higher income (6). Alternatively, this inverse relationship may be because the least increase in wages occurred in governorates that had the highest wages in 1995. Thus, dentists might have settled in governorates with established good economic conditions where other dentists have already settled, confirming the positive association between past and future dentist availability.

The present study was limited by data availability. Because of changes in CAPMAS definitions or units of 
Figure 3 Governorates showing variation in number of dentists to 1000 population in 1995-1999, 2000-2004, 2005-2009 and 2010-2014

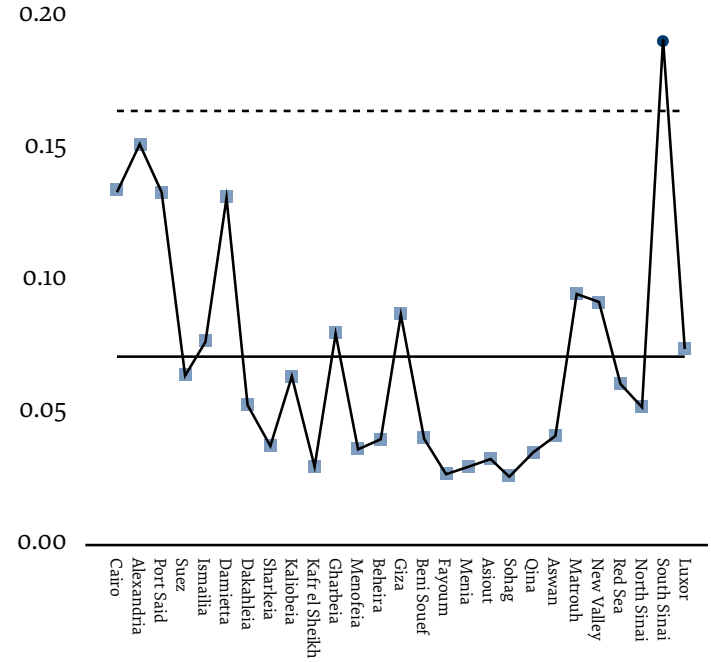

Dentists per 1000 population (1995-1999) South Sinai $>3 \sigma$

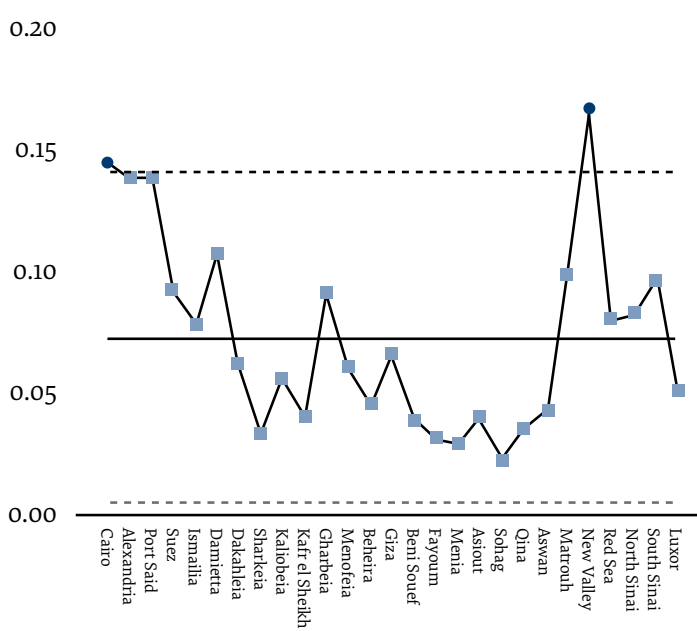

Dentists per 1000 population (2000-2004) Cairo and New Valley $>3 \sigma$
0.5

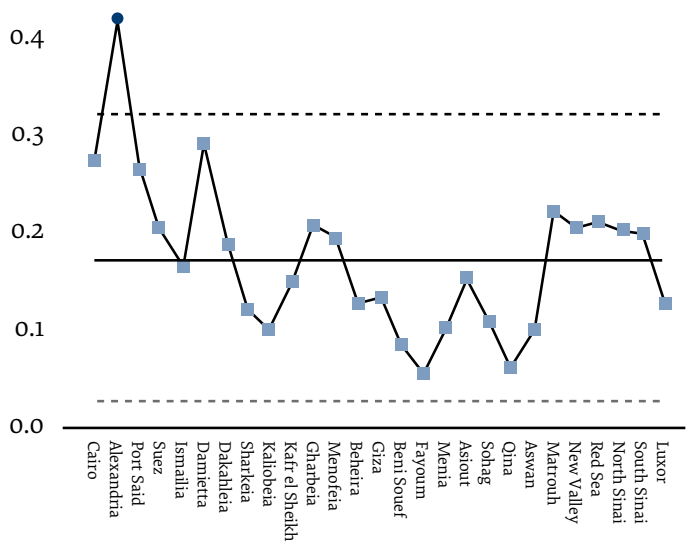

Dentists per 1000 population (2010-2014): Alexandria $>3 \sigma$

Control rule violation: $\square$ No $\bullet$ Yes

reporting, it was not possible to split dentist availability by sector (public vs private) or specialty or urban/ rural location, and this might have obscured some associations. The study was also liable to ecological fallacy since data were reported at aggregate level. Some of the nonsignificant associations may be explained by study power issues, which might have caused some falsenegative associations. The inability to increase sample size because of the fixed number of governorates was addressed by reporting partial $\eta^{2}$ as a measure of effect size to show the relative strength of the explanatory variables, even in the absence of statistical significance. Ecological studies demonstrate macrolevel associations and give insights into the impact of large-scale changes on healthcare systems. The strength of this study lay in its duration, which allowed assessment of longterm effects of supply, potential demand and economic changes on dentist availability. The longitudinal design also made possible before and after study of changes in response to naturally occurring events, such as extending health insurance coverage, opening new dental schools, and major political changes. The present findings may apply to developing countries with economic challenges, large population size and shortage of dentists. These conditions may coexist to various degrees so that direct generalization to neighbouring countries should be avoided.

The present study has implications for oral health services research in Egypt and other MENA countries to assess the extent and impact of within-region 
dentist mobility on oral health outcomes. Research is needed to assess the number of dentists in the public and private sectors in addition to perceptions about dentist availability, how patients have their needs covered in dentist-shortage areas, and the impact of interventions aimed at workforce retention. The study also has healthcare policy implications. Some of the factors affecting dentist availability may be beyond the direct control of policy-makers but should be considered during workforce planning. For example, geopolitical factors limiting the development of some southern governorates, such as Qina and Fayoum, cannot be redressed only by health policy planners but need a holistic development framework. Similarly, the impact of unrest on the population size and number of dentists in North Sinai cannot be reversed within the healthcare system. Concerted efforts are needed to retain graduates in the national workforce and encourage them to settle in governorates with chronic shortage of dentists. There is a need to revisit the existing law of compulsory service for recent graduates and mandatory service in remote locations as a prerequisite for promotion (30). These laws do not seem to be enough to address the problem of shortage of dentists, although reports from Thailand, South Africa and Indonesia show that compulsory service supported by financial incentives may be successful (31-33).
In 2018, the Universal Health Care (UHC) law was enacted in Egypt. It includes dental care provided through the family health model (34). Previous research showed that dentists working in family health clinics expressed concerns about the availability and affordability of services to patients (35). If the new law can reduce the financial burden to patients, and the accompanying restructuring of the healthcare system provides adequate financial incentives to dentists, the economic constraints affecting the shortage of dentists may be addressed. Prospective and controlled studies assessing the impact of UHC and healthcare system restructuring are needed.

\section{Conclusion}

Despite the increase in dental graduates in Egypt over 20 years, about $75 \%$ of the population live in governorates with a shortage of dentists. Our study suggests that the problem is related to high attrition rates. With the high rate of population growth in Egypt, differences between governorates in dentist availability were mostly explained by previous availability and economic conditions. Offering financial incentives to dentists to encourage settling in areas of shortage and extending UHC to larger segments of the population may reduce the impact of economic constrains on providers and users of dental care, leading to better dentist availability.

\section{Acknowledgement}

The authors thank the staff of CAPMAS for data collection.

\section{Funding None.}

Competing interests: None declared.

\section{Disponibilité des dentistes en Égypte : étude sur 20 ans de l'offre, de la demande potentielle et des facteurs économiques}

\section{Résumé}

Contexte : L'Égypte est l'un des pays les plus peuplés de la Région de la Méditerranée orientale, avec des nombres historiquement élevés de professionnels qualifiés fournissant leurs services sur le territoire national et à l'étranger. Des données sur la disponibilité des dentistes sont nécessaires à la planification de la production et de la formation des professionnels.

Objectifs: Nous avons examiné la disponibilité des dentistes en Égypte au moyen des paramètres suivants: 1) changements sur 20 ans ; 2) répartition territoriale; et 3) liens avec l'offre, la demande potentielle de soins et les conditions économiques.

Méthodes : Dans la présente étude écologique (1995-2014), nous avons utilisé des données de l'Agence centrale pour la mobilisation du public et la statistique. Le critère de jugement était la disponibilité des dentistes (nombre de dentistes pour 1000 habitants). Les variables explicatives étaient les suivantes : 1) taille de la population ; 2) nombre de diplômés en médecine dentaire ; 3) disponibilité de dentistes précédente ; 4) augmentation des salaires ; et 5) pourcentage de la population se déplaçant dans le pays afin de trouver du travail. Pour évaluer la variation dans la disponibilité des dentistes, nous avons utilisé le contrôle statistique du processus et l'auto-corrélation spatiale. L'effet des variables explicatives a été évalué au moyen de modèles linéaires généraux avec $\eta^{2}$ partiel pour mesurer la taille de l'effet.

Résultats : Le nombre de dentistes pour 1000 habitants était réparti de manière aléatoire sur le territoire national et atteignait 0,18 en 2014, ce qui indique une pénurie malgré un nombre de diplômés en médecine dentaire en augmentation depuis $1995(667,1 \%)$. La disponibilité des dentistes précédente $\left(\eta^{2}=0,60\right)$ et l'augmentation des salaires $\left(\eta^{2}\right.$ $=0,48)$ avaient les effets les plus importants sur la disponibilité des dentistes. 
Conclusions: L'Égypte est confrontée à un problème de pénurie de dentistes, qui n'a pas été compensé par l'augmentation du nombre de diplômés en médecine dentaire. La situation pourrait être améliorée par de meilleures conditions économiques ainsi que par l'intégration des soins de santé dans le plan de développement national.

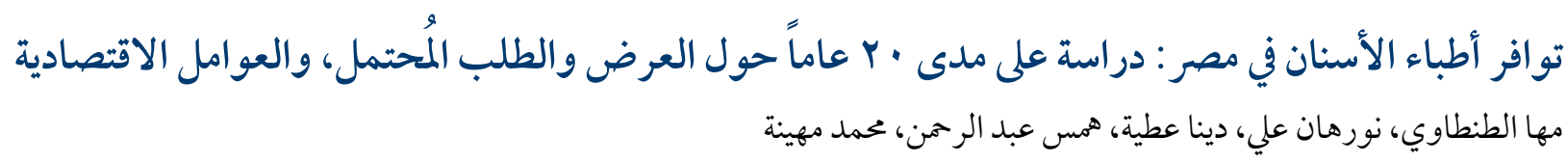

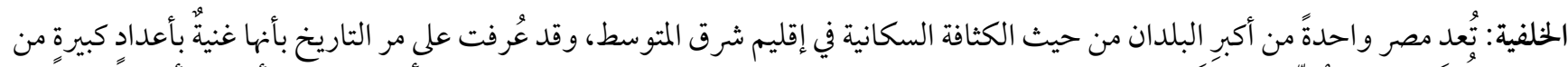

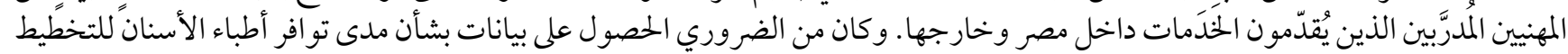
بشأن إعداد القوى العاملة وتدريبها.

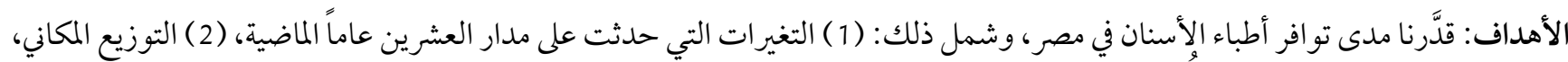

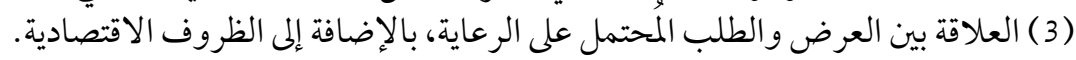

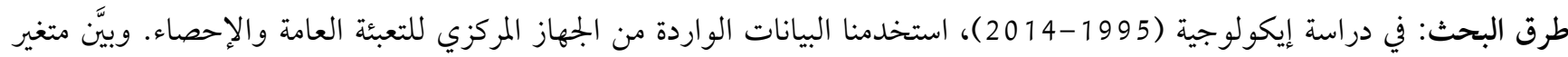

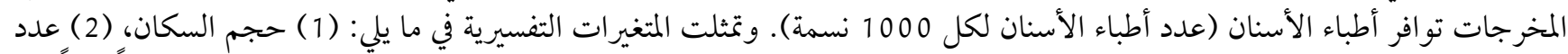

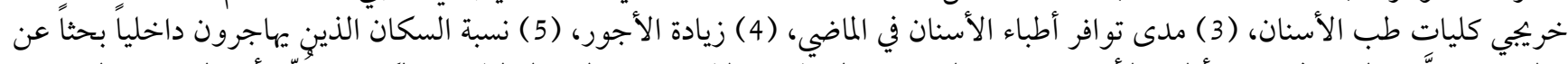

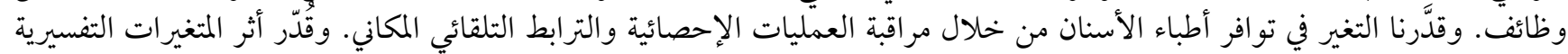

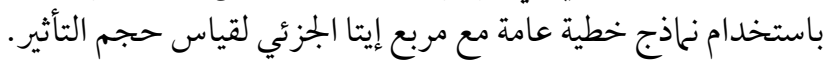

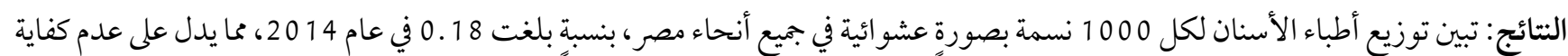

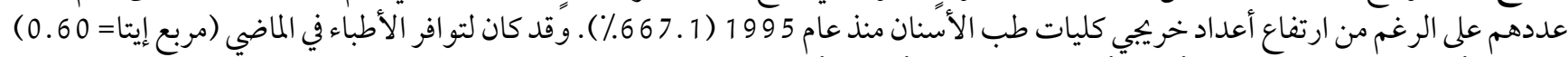

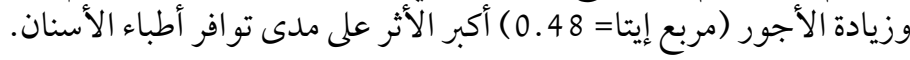

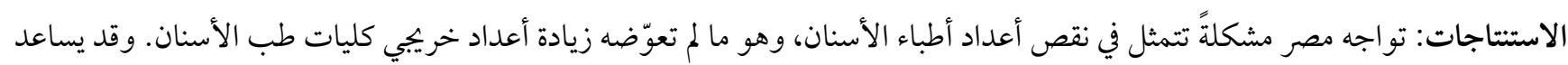

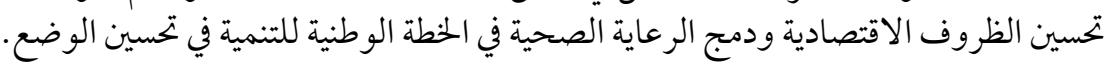

\section{References}

1. Rephann TJ, Wanchek TN. Filling the gaps: explanations for disparities in the distribution of dentists among U.S. counties. J Reg Anal Policy. 2016;46(1):60-71.

2. Schulz M, Kunst AE, Brockmann H. High educational attainment moderates the association between dental health-care supply and utilization in Europe. Eur J Oral Sci. 2016 Feb;124(1):52-61. http://dx.doi.org/10.1111/eos.12237 PMID:26715618

3. World Health Organization (WHO). Global Health Observatory (GHO) data. Density of dentistry personnel (total number per 1000 population, latest available year) [website]. World Health Organization (http://origin.who.int/gho/health_workforce/dentistry_density/en/, accessed 30 January 2020).

4. Guay AH. Access to dental care: solving the problem for underserved populations. J Am Dent Assoc. 2004 Nov;135(11):1599-605. http://dx.doi.org/10.14219/jada.archive.2004.0088 PMID:15622666

5. Jiang HJ, Begun JW. Dynamics of change in local physician supply: An ecological perspective. Soc Sci Med. 2002 May;54(10):1525-41. http://dx.doi.org/10.1016/S0277-9536(01)00132-o PMID:12061486

6. Kuthy RA, McKernan SC, Pooley M, Zimmerman MB. Relationship between community-level variables and number of general dentists. J Am Dent Assoc. 2018 Apr;149(4):308-16. http://dx.doi.org/10.1016/j.adaj.2017.11.007 PMID:29478702

7. Abid A. Oral health in Tunisia. Int Dent J. 2004 Dec;54(6 Suppl 1):389-94. http://dx.doi.org/10.1111/j.1875-595x.2004.tbooo16.x PMID:15631102

8. Behbehani JM, Scheutz F. Oral health in Kuwait. Int Dent J. 2004 Dec;54(6 Suppl 1):401-8. http://dx.doi.org/10.1111/j.1875595x.2004.tbooo18.x PMID:15631104

9. Gallagher JE, Manickam S, Wilson NHF. Sultanate of Oman: building a dental workforce. Hum Resour Health. 2015;13(1):50. http://dx.doi.org/10.1186/s12960-015-0037-z.

10. Gächter M, Schwazer P, Theurl E, Winner H. Regional density of private dentists: Empirical evidence from Austria. Community Dent Oral Epidemiol. 2014 Feb;42(1):20-9. http://dx.doi.org/10.1111/cdoe.12054 PMID:23725403

11. Hsueh Y-SA, Lee S-YD, Huang Y-TA. Effects of Global Budgeting on the Distribution of Dentists and Use of Dental Care in Taiwan. Health Serv Res. 2004 Dec;39(6 Pt 2):2135-53. http://dx.doi.org/10.1111/j.1475-6773.2004.00336.x PMID:15544648

12. Population, total [website]. World Bank (https://data.worldbank.org/indicator/SP.POP.TOTL, accessed 30 January 2020). 
13. Global Health Observatory data repository, dentistry personnel [website]. World Health Organization (http://apps.who.int/gho/ data/view.main.HWFDENv, accessed 30 January 2020).

14. Health sector cooperation planning survey in Arab Republic of Egypt. final report. Japan International Cooperation Agency; 2017 (http://open_jicareport.jica.go.jp/pdf/12285300.pdf, accessed 30 January 2020).

15. Ministry of Higher Education annual statistics (2014) [website]. Cairo: Ministry of Higher Education (http://portal.mohesr.gov. eg/ar-eg/Pages/statistics.aspx, accessed 30 January 2020) (in Arabic).

16. Central Agency for Public Mobilization and Statistics Records 1995-2014 [website]. Central Agency of Public Mobilization and Statistics (CAPMAS) (http://www.webcitation.org/73IAhXF2K, accessed 30 January 2020) (in Arabic).

17. van de Glind EMM, Willems HC, Eslami S, Abu-Hanna A, Lems WF, Hooft L et al. Estimating the time to benefit for preventive drugs with the statistical process control method: an example with alendronate. Drugs Aging. 2016 May;33(5):347-53. http://dx. doi.org/10.1007/s40266-016-0344-7 PMID:26884390

18. Goodchild MF. Spatial autocorrelation. Geo Books; 1986.

19. Rules of thumb on magnitudes of effect sizes [website]. MRC Cognition and Brain Sciences Unit, University of Cambridge. (http://imaging.mrc-cbu.cam.ac.uk/statswiki/FAQ/effectSize, accessed 30 January 2020).

20. Designated health professional shortage areas statistics. Bureau of Health Workforce, Health Resources and Services Administration Services, US Department of Health and Human Services (https://ersrs.hrsa.gov/ReportServer?/HGDW_Reports/BCD_ HPSA/BCD_HPSA_SCR50_Qtr_Smry_HTML\&rc:Toolbar=fals, accessed 26 October 2018).

21. Cartes-Velasquez RA. Exponential growth of dental schools in Chile: effects on academic, economic and workforce issues. Braz Oral Res. 2013 Dec;27(6):471-7. http://dx.doi.org/10.1590/S1806-83242013000600005.

22. Vundavalli S. Dental manpower planning in India: current scenario and future projections for the year 2020. Int Dent J. 2014 Apr;64(2):62-7. http://dx.doi.org/10.1111/idj.12063 PMID:24180215

23. El Tantawi M, Gaffar B, Arheiam A, AbdelAziz W, Al-Batayneh OB, Alhoti MF, et al. Dentists' intention to report suspected violence: a cross-sectional study in eight Arab countries. BMJ Open. 2018 Mar 30;8(3):e019786. http://dx.doi.org/10.1136/bmjopen-2017-019786 PMID:29602845

24. Ozden C. United Nations expert group meeting on international migration and development in the Arab region: brain drain in Middle East \& North Africa - the patterns under the surface. Beirut: Population Division, Department of Economic and Social Affairs, United Nations Secretariat; 2006 (https://www.un.org/en/development/desa/population/events/pdf/expert/11/ P10_Ozden.pdf, accessed 30 January 2020).

25. Hirata S, Okawa Y, Sugito H, Mataki S, Sakayori T, Maki Y, et al. Does mandatory postgraduate clinical training worsen geographic distribution of dentists in Japan? Bull Tokyo Dent Coll. 2013;54(3):141-8. http://dx.doi.org/10.2209/tdcpublication.54.141 PMID:24334627

26. Bailit HL, Beazoglou TJ. State financing of dental education: impact on supply of dentists. J Dent Educ. 2003 Dec;67(12):1278-85. PMID:14733258

27. Matsumoto M, Inoue K, Bowman R, Noguchi S, Kajii E. Physician scarcity is a predictor of further scarcity in US, and a predictor of concentration in Japan. Health Policy (New York). 2010 May;95(2-3):129-36. http://dx.doi.org/10.1016/j.healthpol.2009.11.012.

28. Squires A, Uyei SJ, Beltrán-Sánchez H, Jones SA. Examining the influence of country-level and health system factors on nursing and physician personnel production. Hum Resour Health. 2016;14: Article number 48. http://dx.doi.org/10.1186/s12960-016-0145-4.

29. Health Sytem Profile, Egypt 2006. World Health Organization; 2006 (http://apps.who.int/medicinedocs/documents/s17293e/ s17293e.pdf, accessed 30 January 2020).

30. Physicians' manual - compulsory Service March 2007. Ministry of Health and Population, Egypt (https://www.ems.org.eg/ emsadmin/uploads/userfiles/file/\%D8\%AF\%D9\%84\%D9\%8A\%D9\%84\%20\%D8\%A7\%D8\%B7\%D8\%A8\%D8\%A7\%D8\%A1\%20\%D8\%A7\% D9\%84\%D8\%AA\%D9\%83\%D9\%84\%D9\%8A\%D9\%81\%202007.pdf, accessed 10 April 2019).

31. Wiwanitkit V. Mandatory rural service for health care workers in Thailand. Rural Remote Health. 2011;11:1583. https://pdfs. semanticscholar.org/1257/0a7c939f58309b21ee015a7654cfa95cc84e.pdf

32. Hatcher AM, Onah M, Kornik S, Peacocke J, Reid S. Placement, support, and retention of health professionals: national, cross-sectional findings from medical and dental community service officers in South Africa. Hum Resour Health. 2014 Feb 26;12:14. http://dx.doi.org/10.1186/1478-4491-12-14 PMID:24571826

33. Efendi F. Health worker recruitment and deployment in remote areas of Indonesia. Rural Remote Health. 2012;12:2008. PMID:22670640

34. Egypt: health systems strengthening towards universal health coverage [website]. World Health Organization (http://www. emro.who.int/egy/programmes/health-systems-strengthening.html, accessed 30 January 2020).

35. El Tantawi M, El-Din Hamza MA, Sabry MM. Dentists' perception of primary health care services in family health and mother and child health clinics in Alexandria, Egypt. East Mediterr Health J. 2017 Mar 30;23(2):73-9. http://dx.doi. org/10.26719/2017.23.2.73 PMID:28383095 